\title{
Analisis Rugi-Rugi Daya Jaringan Distribusi Penyulang POLDA Area Makassar Utara dengan Menggunakan ETAP 12.6
}

\author{
Sugianto \\ Program Studi Teknik Elektro \\ Universitas Muslim Indonesia, \\ Makassar - Indonesia \\ puangsugianto@gmail.com
}

\author{
Arif Jaya \\ Program Studi Teknik Elektro \\ Universitas Muslim Indonesia, \\ Makassar - Indonesia
}

\author{
Bayu Adrian Ashad \\ Program Studi Teknik Elektro \\ Universitas Muslim Indonesia \\ Makassar - Indonesia \\ Bayuadrianashad@gmail.com
}

\begin{abstract}
Abstrak - Analisis Rugi-rugi Daya Saluran Distribusi Tegangan Menengah Penyulang Polda, bertujuan tegangan menengah penyulang polda. Perhitungan Rugi-rugi daya saat ini banyak menggunakan aplikasi computer, tujuannya untuk mempermuda dan mendapatkan hasil yang cepat dan akurat pada penelitian menggunakan software ETAP 12.6, disamping itu juga dilakukan perhitungan manual kemudian membandingkan dengan hasil dari software ETAP. Rugi-rugi pada Penyulang Polda menggunakan Software Etap adalah $600,9 \mathrm{~kW}$ dan perhitungan manual 509,8 kW, Besar rugi-rugi Daya yang terbesar ada line 53 yaitu dari bus 121 ke bus 122 dan yang paling kecil terjadi pada line 98 yaitu dari bus 200 ke bus 201.
\end{abstract}

Keywords - Rugi-rugi daya, Jaringan tegangan menengah, Software ETAP 12.6

\section{PENDAHULUAN}

Rugi-rugi jaringan adalah selisih antara $\mathrm{kWH}$ yang disalurkan dengan $\mathrm{kWH}$ terjual ke pelanggan. Disini tampak jelas bahwa PLN Distribusi mengalami kerugian akibat Rugi-rugi tersebut. Secara garis besar Rugi-rugi dapat dikategorikan menjadi dua yaitu Rugi-rugi teknis dan Rugi-rugi non teknis. Rugi-rugi teknis adalah rugi-rugi yang disebabkan oleh sifat dari material atau peralatan jaringan, luas penampang penghantar, jarak dan factor kerja. Sedangkan rugi-rugi non teknis adalah rugi-rugi yang disebabkan oleh kesalahan pemasangan dan kerusakan dari material atau peralatan jaringan serta pencurian [1].

Kualitas daya listrik yang kurang baik dapat diketahui dari sisi beban, sumber dan distribusinya. Permasalahan yang sering terjadi adalah adanya arus atau tegangan yang berkurang karena penggunaan beban nonlinear seperti computer, mesin fotocopy, mesin fax, printer, lampu, dan penghantar serta distribusinya, sehingga dapat menyebabkan adanya kerugian daya. Selain itu kondisi daya listrik yang tidak stabil dapat memperpendek umur trafo, motor, kapasitor dan alat-alat lainnya. Masalah lainnya adalah ketidakseimbangan penggunaan beban pada tiap fasa menyebabkan munculnya arus pada penghantar netral yang juga berdampak adanya kerugian daya.
Berdasarkan daya listrik yang disalurkan mengacu pada kebutuhan konsumen akan daya listrik bersamaan dengan waktu, ini mengakibatkan terjadinya " beban puncak" pada kurva beban. Begitu juga kebutuhan daya listrik di area wilayah makassar utara, mengalami puncak yang ada pada sore hari, karena selain penggunaan alat elektronika, juga seluruh alat penerangan yang menyala.

Losses jaringan adalah selisih antara KWH beli PLN Distribusi dengan KWH jual ke pe-langgan. Disini tampak jelas bahwa PLN Distribusi mengalami kerugian akibat losses tersebut, sehingga PLN Distribusi harus menekan losses tersebut agar kerugian PLN tidak terlalu besar [2].

Dengan meningkatnya beban, besarnya rugi-rugi dan Jatuh tegangan oleh adanya tahanan pada penghantar akan semakin meningkat pula. Jatuh tegangan terjadi cukup besar apabila jarak pelanggan dengan gardu distribusi terlalu jauh sehingga menaikan rugi-rugi daya (Power losses) secara signifikan. Rugi-rugi daya (Power losses) berbanding lurus dengan tahanan penghantar dan kuadrat arus beban. Selain itu rugi-rugi daya (Power losses) dapat juga disebabkan non teknis [3].

Disamping itu masalah tegangan, bagian-bagian instalasi yang berbeban lebih dan rugi-rugi dalam jaringan, merupakan masalah yang perlu dicatat dan dianalisa secara terus-menerus untuk dijadikan masukkan dan pengembangan. Berdasarkan permasalahan diatas peneliti akan mengevaluasi rugi-rugi yang mampu memberikan informasi tentang kerugian daya listrik pada penyulang Polda Area Makassar Utara". Dalam penelitian ini penulis menggunakan ETAP (Electronic Transient And Program).

\section{TEORI DASAR}

Jaringan distribusi terdiri atas dua bagian, yang pertama adalah jaringan tegangan menengah/primer (JTM), yang menyalurkan daya listrik dari gardu induk subtransmisi ke gardu distribusi, jaringan distribusi primer menggunakan tiga kawat atau empat kawat untuk tiga fasa. Jaringan yang kedua adalah jaringan tegangan rendah (JTR), yang menyalurkan daya listrik dari gardu distribusi ke konsumen, dimana sebelumnya tegangan tersebut 
ditransformasikan oleh transformator distribusi dari $20 \mathrm{kV}$ menjadi 380/220 Volt, jaringan ini dikenal pula dengan jaringan distribusi sekunder [4].

Jaringan distribusi sekunder terletak antara transformator distribusi dan sambungan pelayanan (beban) menggunakan penghantar udara terbuka atau kabel dengan sistem tiga fasa empat kawat (tiga kawat fasa dan satu kawat netral). Dapat kita lihat gambar dibawah proses penyedian tenaga listrik bagi para konsumen. Sistem distribusi primer digunakan untuk menyalurkan tenaga listrik dari gardu induk distribusi ke pusat beban. Sistem ini dapat menggunakan saluran kabel udara, maupun kabel tanah sesuai dengan tingkat keandalan yang diinginkan dan kondisi serta situasi lingkungan. Saluran distribusi ini direntangkan sepanjang daerah yang akan di suplay tenaga listrik sampai ke pusat beban. Terdapat bermacam-macam bentuk rangkaian jaringan distribusi primer [5].

Rugi-rugi daya adalah hilangnya pasokan daya pada proses pengiriman daya listrik dari sumber ke beban (konsumen) melalui penghantar. Susut daya listrik untuk saluran tiga fasa dinyatakan oleh persamaan [6]:

dengan:

$$
P L=3 . \mathrm{I}^{2} \times \mathrm{R} L
$$

$$
\begin{aligned}
& P L=\text { Susut Daya }(\text { Watt }) \\
& \mathrm{R}=\text { Tahanan kawat per fasa }(\Omega / \mathrm{Km}) \\
& \mathrm{I}=\text { Arus Beban }(\mathrm{A}) \\
& \mathrm{L}=\text { Panjang saluran }(\mathrm{Km})
\end{aligned}
$$

ETAP adalah suatu software analisis yang comprehensive untuk mendesain dan mensimulasikan suatu sistem rangkaian tenaga. Analisis yang ditawarkan oleh ETAP yang digunakan oleh penulis adalah drop tegangan, power factor, dan losses jaringan. ETAP juga bisa memberikan warning terhadap bus - bus yang under voltage dan over voltage sehingga pengguna bisa mengetahui bus mana yang tidak beroperasi optimal [7].

ETAP memungkinkan anda untuk bekerja secara langsung dengan diagram satu garis grafis dan sistem kabel bawah tanah raceway. Program ini telah dirancang berdasarkan tiga konsep kunci [8]:

- Virtual Reality Operasi

- Integrasi total Data

- Kesederhanaan di Data Entri

\section{METODOLOGI PENELITIAN}

Untuk menganalisa suatu rangkaian diperlukan data rangkaian yang lengkap dan akurat sehingga hasil perhitungan ETAP bisa dipertanggungjawabkan. ETAP mengintegrasikan data-data rangkaian tenaga listrik seperti kapasitas pembangkit, panjang jaringan, resistansi jaringan per $\mathrm{km}$, kapasitas busbar, ranting trafo,impedansi urutan nol, positif, dan negatif suatu peralatan listrik seperi trafo, generator dan penghantar

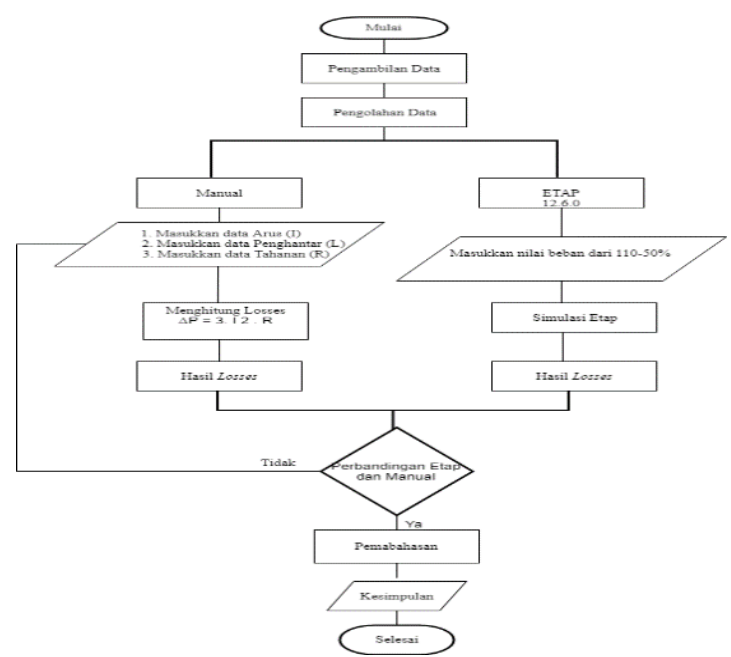

Gambar 1. Flowchart Penelitian

\section{HASIL DAN PEMBAHASAN}

Analisa Losses dengan ETAP 12.6

Langkah-langkah yang dilakukan untuk mencari nilai losses dengan ETAP 12.6 adalah dengan menghitung persentase losses pada saat sistem beroperasi, dimana perhitungan dimulai saat beban dalam keadaan $100 \%$ sampai dengan $50 \%$. Kemudian dilakukan perbandingan losses dengan menaikkan beban dari $100 \%$ menjadi $110 \%$. System jaringan polda pada saat beban dalam kondisi $100 \%$

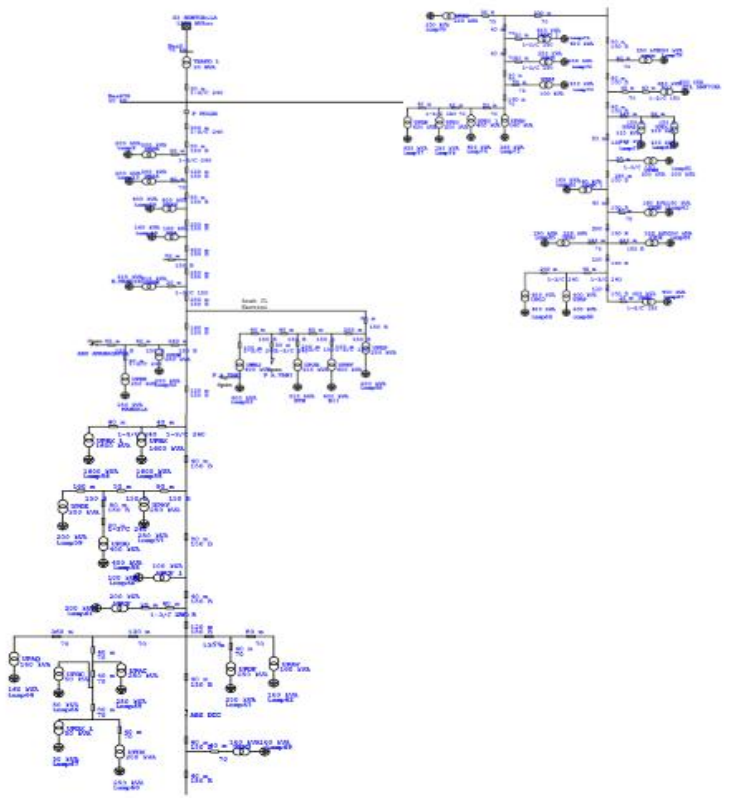

Gambar 2. Sistem Jaringan Penyulang Polda saat beban dalam kondisi $100 \%$

Hasil Report Losses Penyulang Polda saat beban dalam kondisi $100 \%$. Dari hasil report di atas dapat dilihat bahwa besar losses pada saat beban dalam kondisi $100 \%$ adalah 507,6 kW.

Perhitungan Manual Rugi-Rugi Daya Pada Penyulang Polda Perhitungan secara manual hanya diambil dari data $100 \%$ yang ada. Perhitungan dilakukan dengan mengambil data per line dan kabel yang ada pada penyulang polda. 
Untuk Line 53 dengan jenis kabel AAAC diketahui I = 400,7 A, dapat dilihat pada Bus 121 . Adapun nilai $\mathrm{R}$, diambil dari parameter line 53 dimana $\mathrm{R}=0,2696 \mathrm{ohm}$ per $1 \mathrm{~km}$, pada saat beroperasi dengan suhu $75^{\circ} \mathrm{C}$. Kemudian panjang line $=0,45 \mathrm{~km}$, sehingga nilai $\mathrm{R}=0,2696 \times 0,45=$ $0.12132 \Omega$.

$$
\begin{aligned}
\Delta P \text { Losses } & =3 . \mathrm{I} . \mathrm{R} \\
& =3 .(400,7)^{2} \cdot 0.12132 \\
& =58.437 \mathrm{Watt} \\
& =58.437 \mathrm{~kW}
\end{aligned}
$$

Untuk Line 98 dengan jenis kabel AAAC diketahui $\mathrm{I}=2,8 \mathrm{~A}$, dapat dilihat pada Bus 198 . Adapun nilai $\mathrm{R}$, diambil dari parameter line 98 dimana $\mathrm{R}=0,5247 \mathrm{ohm}$ per $1 \mathrm{~km}$, pada saat beroperasi dengan suhu $75^{\circ} \mathrm{C}$. Kemudian panjang line $=0,08 \mathrm{~km}$, sehingga nilai $\mathrm{R}=0,5247 \times 0,08=$ $0.041976 \Omega$.

$$
\begin{aligned}
\Delta P \text { Losses } & =3 . \mathrm{I}^{2} \cdot \mathrm{R} \\
& =3 \cdot(2,8) 2.0 .041976 \\
& =0.98727 \mathrm{Watt} \\
& =0.00098 \mathrm{~kW}
\end{aligned}
$$

Jumlah Total Losses Pada Penyulang Polda Saat beban $100 \%$, dapat dilihat pada tabel berikut ini :

Table 1. Total losses pada Penyulang Polda

\begin{tabular}{c|c|c}
\hline No & Nama & Losses (kW) \\
\hline 1. & Total Trafo Pada GI Bontoala & 50,9 \\
\hline 2. & Total Line (SUTM) & 251,6 \\
\hline 3. & Total Cable (SKTM) & 20,6 \\
\hline 4. & Total Gardu Pada Penyulang Polda & 174,4 \\
\hline \multicolumn{2}{|c|}{ Jumlah } & 497,5 \\
\hline
\end{tabular}

Jadi, arus yang mengalir dari GI Bontoala sebesar 428,4 A

Pada gambar 3 dan 4 berikut ini, dapat dilihat perbandingan Losses pada setiap line (SUTM) dengan menggunakan simulasi Etap dan perhitungan manual di Penyulang Polda saat beban $100 \%$ atau dalam kondisi awal.

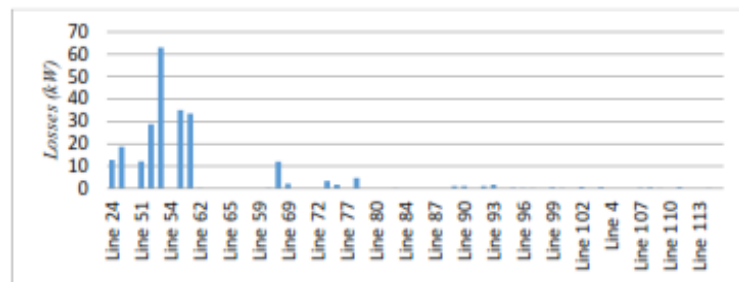

Gambar 3. Hasil Losses pada Line (SUTM)

Penyulang Polda dengan menggunakan simulasi Etap

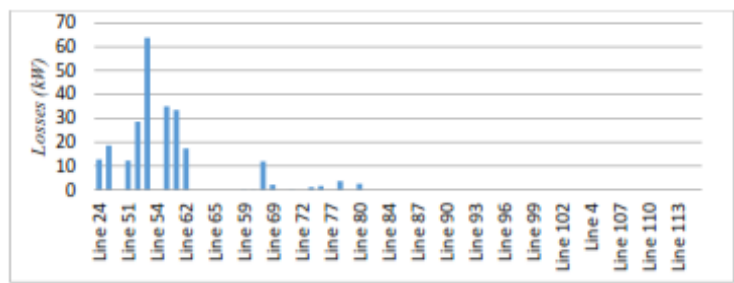

Gambar 4. Hasil Losses pada Line (SUTM) Penyulang Polda dengan perhitungan manual
Pada gambar 3 dan 4 diatas, tampak losses terbesar berada pada line 53 yaitu dari bus $121 \mathrm{ke}$ bus 122 sebesar $63.1 \mathrm{~kW}$ (simulasi Etap) dan 58,4 $\mathrm{kW}$ (perhitungan manual) dengan arus yang mengalir pada line tersebut sebesar 400,7 A. Sedangkan losses terendah berada pada line 98 yaitu dari bus $200 \mathrm{ke}$ bus 201 sebesar 0,0 kW (simulasi Etap) dan 0.0009 $\mathrm{kW}$ (perhitungan manual) dengan arus yang mengalir pada line tersebut sebesar 2,8 A. Penyebab tingginya losses pada line 53 dikarenakan beban pada line 53 relatif tinggi sehingga arusnya besar yang dapat menimbulkan panas pada penghantar serta dapat merusak alat dan menimbulkan losses, sementara itu losses pada line 98 rendah dikarenakan beban pada line 98 yang relatif rendah sehingga arusnya juga rendah. Adapun perbedaan losses antara perhitungan menggunakan software Etap dengan perhitungan manual pada gambar tersebut tidak terlalu signifikan.

\section{KESIMPULAN}

Dari hasil Evaluasi Losses Pada Jaringan Distribusi Area Makassar Utara di ULP Karebosi dengan Etap 12.6.0 dapat disimpulkan sebagai berikut: Jumlah Losses Penyulang Polda dengan menggunakan simulasi Etap diperoleh nilai sebesar $600,9 \mathrm{~kW}$ dan hasil perhitungan manual sebesar $509,8 \mathrm{~kW}$. Rugi-rugi terbesar pada jaringan tegangan menengah Penyulang Polda rugi-rugi terbesar terjadi di line 53 yaitu dari bus 121 ke bus 122 dan yang paling kecil terjadi di line 98 yaitu dari bus $200 \mathrm{ke}$ bus 201. Besarnya rugi-rugi daya Penyulang Polda disebabkan karena beban pada masing-masing cable dan line tersebut bebannya relatif tinggi sehingga menimbulkan arus yang besar, terbukti pada saat beban dinaikkan menjadi $110 \%$ (over load) maka losses nya juga ikut naik.

\section{DAFTAR PUSTAKA}

[1] R. S. Siregar and R. Harahap, "Perhitungan Arus Netral, Rugi-Rugi, dan Efisiensi Transformator Distribusi 3 Fasa 20 KV/400V Di PT. PLN (Persero) Rayon Medan Timur Akibat Ketidakseimbangan Beban," JET (Journal Electr. Technol., vol. 2, no. 3, pp. 7985, 2017.

[2] Y. Marniati and Q. A. Haifatulah, "Evaluasi Susut Daya Penyulang Cendana $20 \mathrm{kV}$ Pada Gardu Induk Bungaran Dengan ETAP 12.6," J. Tek. Elektro, vol. 7, no. 1, pp. 79-93, 2018.

[3] S. Sabiq, "Estimasi Kerugian Energi Jaringan Distribusi Radial Pada Penyulang NR7 20kV Kota Medan Menggunakan Loss Factor." Institut Teknologi Sepuluh Nopember, 2017.

[4] M. A. H. Sirad, "Analysis of the Potential of Renewable Energy in South Sulawesi as Power Electrical Needs," J. Electr. Technol. UMY, vol. 1, no. 4, pp. 196-201, 2017.

[5] R. F. Sibarani and S. Amien, "Pengaruh Arus 
Netral Terhadap Rugi-Rugi Beban Pada Transformator Distribusi PLN Rayon Johor Medan," Singuda ENSIKOM, vol. 12, no. 33, pp. 49-54, 2015.

[6] R. N. Putri and H. Putranto, "Analisis Perhitungan Losses Pada Jaringan Tegangan Rendah Dengan Perbaikan Pemasangan Kapasitor," TEKNO, vol. 20, no. 2, 2014.

[7] S. Supriyadi, A. H. Paronda, and A. Hasad, "Analisis Power Losses Pada Distribusi Listrik Di Gedung Universitas Islam '45' Bekasi Dengan Menggunakan Software Etap 7.5. 0," JREC (Journal Electr. Electron., vol. 5, no. 2, pp. 153-168, 2017.

[8] S. Khoiriyah and S. T. Agus Supardi, "Analisa Susut Daya Dan Energi Pada Jaringan Distribusi Di Gardu Induk Bringin Penyulang BRG-4 Menggunakan Software ETAP 12.6." Universitas Muhammadiyah Surakarta, 2018. 